\title{
Analisis Portofolio Optimal : Pendekatan Mean Variance Pada Harga Komoditas Pangan di Kota Padang
}

\section{Optimal Portofolio Analysis : Mean Variance Approach on Food Commodity Prices in Padang City}

\author{
Elfa Rafulta $^{1)}$ \& Roni Tri Putra ${ }^{2)}$ \\ 1)Jurusan Pendidikan Matematika, STKIP YDB Lubuk Alung, Telp. (0751)96079 \\ Email: elfarafulta10@gmail.com \\ ${ }^{2)}$ Jurusan Teknik Sipil Politeknik Negeri Padang Kampus Limau Manis Padang \\ Telp. 0751-72590 Fax. 0751-72576 Email: putra_tryronny@yahoo.co.id
}

\begin{abstract}
Investment is a number of commitments or a number of funds or resources made at this time with the aim of obtaining future profits. One method that can be used to form an optimal portfolio is to use the mean variace approach. Asset selection is carried out on food commodities namely rice, eggs, cooking oil, granulated sugar, and red chili. From the data processing it is found that the weight of each commodity is cooking oil (99.95\%), eggs $(0.03 \%)$, granulated sugar $(0.04 \%)$, red chili is negative $(-0.02 \%)$, and rice $(0.00 \%)$. So that it can be estimated that the expected profit is $-0.0024 \%$ and risk is $0.0001 \%$.
\end{abstract}

Keywords : Return, Risk, Investment, Portfolio, Mean Variance

\section{PENDAHULUAN}

Investasi adalah penanaman modal dengan bentuk uang maupun barang yang diharapkan akan memberikan keuntungan yang lebih pada kemudian hari. Investasi dalam bentuk surat berharga (sekuritas) dapat dilakukan pada pasar uang maupun pasar modal. Penanaman modal investasi yang dilakukan pada pasar uang contohnya valuta asing, deposito, dan Sertifikat Bank Indonesia. Penanaman modal yang ditanamkan di pasar modal seperti obligasi dan saham. Untuk investor yang memiliki kemampuan untuk menghadapi risiko bisa menanamkan modal yang dimiliki di pasar modal berupa saham, dengan imbalan pendapatan (return) yang tinggi. Investasi dilakukan untuk memperoleh keuntungan. Kemudian keuntungan digunakan untuk memenuhi kebutuhan hidup kita. Kita hidup dengan berbagai kebutuhan. Semua manusia butuh makan. Tapi tak semua manusia membutuhkan mobil. Banyak yang membutuhkan sambungan internet. Namun tak semua membutuhkan laptop atau komputer.

Kebutuhan-kebutuhan itu bisa kita golongkan berdasarkan intensitas atau kepentingannya yakni: Primer, Sekunder, dan Tersier. Kebutuhan primer adalah kebutuhan yang berkaitan dengan mempertahankan hidup secara layak. Kebutuhan ini mendasar dan harus dipenuhi manusia. Kebutuhan primer terdiri dari sandang (pakaian), pangan (makan), dan papan (tempat tinggal). Tanpa pangan, manusia akan meninggal. Begitu pula tanpa sandang dan papan. Jika kebutuhan sandang dan pangan tidak tercukupi maka manusia akan tersiksa hidupnya dan sering juga rentan terserang penyakit. Kebutuhan sekunder adalah kebutuhan yang berkaitan dengan usaha menciptakan atau menambah kebahagiaan hidup. Kebutuhan sekunder berupa penunjang hidup. Kebutuhan ini bisa ditunda pemenuhannya setelah kebutuhan primer dipenuhi. Kebutuhan tersier adalah kebutuhan yang berkaitan dengan usaha menciptakan atau meningkatkan harga diri, prestise atau gengsi. Kebutuhan ini bisa dipenuhi setelah 
kebutuhan primer dan sekunder terpenuhi. Contohnya liburan ke luar negeri, perhiasan, dan barang bermerk. Seiring dengan perkembangan zaman, kebutuhan manusia pun juga berkembang.

Untuk memenuhi kebutuhan hidupnya tersebut, manusia melakukan suatu kegiatan dalam bentuk usaha. Kegiatan manusia yang dilakukan untuk memenuhi kebutuhan hidupnya disebut kegiatan ekonomi. Secara umum, kegiatan ekonomi yang dilakukan manusia dapat digolongkan atas tiga jenis. Menghasilkan atau memproduksi berbagai jenis barang dan jasa, Mendistribusikan barang dan jasa, Mengkonsumsi barang-barang dan jasa. Kegiatan usaha manusia yang dilakukan untuk memenuhi kebutuhan hidupnya, yang dilakukan oleh masyarakat sangat beragam, diantarany bidang pertanian, perdagangan, jasa dan industri.

Sebagian besar masyarakat melakukan kegiatan perdagangan untuk memenuhi kebutuhan hidupnya. Kalimat yang sangat sering terdengar di telinga kita yaitu "Dengan pengorbanan (modal) yang sekecil-kecilnya untuk memperoleh hasil (keuntungan) yang sebesar-besarnya (Adam Smith)." Jika teori ini diterapkan oleh para pegawai dan karyawan yang terjadi adalah akan menumbuhkan etos kerja yang rendah. Kalau perlu dengan bekerja semaunya mereka mendapatkan gaji yang besar. Maka tidak heran jika Anda sering melihat banyak pegawai negeri ataupun karyawan swasta yang bekerja dengan seenaknya sendiri. Tidak jarang kita melihat ada orang berseragam PNS berkeliaran di pasar-pasar, mal-mal pada jam kerja. Itulah akibat salahnya dari penerapan teori ini. Lebih parahnya lagi banyak yang menerapkan teori ini sejak awal mereka sebelum bekerja. Masuk bekerja dengan memberikan uang sogokan, akhirnya untuk mendapatkan hasil yang sebesar-besarnya mereka melakukan korupsi. Jika teori ini diterapkan oleh para pedagang, maka memang terjadi, dengan modal yang sekecil-kecilnya mereka akan berusaha mencari keuntungan yang sebesar-besarnya.
Dampak buruknya mereka akan mengurang timbangan ataupun menjual produk yang kualitasnya tidak baik, hanya demi mendapatkan untung yang berlipat-lipat.

Untuk memperoleh keuntungan yang besar. Banyak hal yang bisa pedagang lakukan, diantaranya adalah membuat portofolio dari modal yang dimilikinya. Hal ini bisa dilakukan dengan menanamkan modalnya pada beberapa aset dagang. Dalam penelitian ini penulis mengkaji tentang aset dagang pangan. Dalam membentuk portofolio, pedagang sebagai investor harus memperhatikan tiga hal dasar berkenaan dengan instrument keuangan yang akan dipilih sebagai elemen portofolio. Tiga hal penting tersebut adalah risiko, return atau imbal hasil pengembalian yang diharapkan, dan hubungan antara imbal hasil dengan risiko. Dengan membentuk portofolio, risiko yang harus ditanggung pedagang akan lebih kecil dibandingkan dengan risiko aset secara individual. Lebih lanjut, agar mendapatkan imbal hasil yang optimum, pedagang dapat melakukan suatu usaha yaitu diversifikasi portofolionya sehingga risiko yang harus ditanggung berkurang. Hal ini telah dibuktikan dalam penelitian yang dilakukan oleh Markowitz (1952) dimana risiko investasi dapat diminimalisir dengan menggabungkan beberapa aset dalam suatu portofolio. Diversifikasi dapat dilakukan dengan berbagai cara, salah satunya adalah diversifikasi yang menggunakan pendekatan Mean Variance Model yang ditemukan oleh Markowitz.

\section{METODOLOGI}

\section{Pembentukan Portofolio}

Sebuah portofolio adalah kombinasi linier dari beberapa aset, $\mathrm{y}=\mathrm{w}_{1} \mathrm{x}_{1}+. .+\mathrm{w}_{\mathrm{p}} \mathrm{x}_{\mathrm{p}}$. Dalam pembentukan portofolio, setiap aset memiliki kontribusi terhadap modal total sebesar bobot $w_{i}$. Komposisi bobot $w=\left(w_{1}, \ldots, w_{k}\right)^{\mathrm{T}}$ dalam portofolio bisa ditentukan dengan cara intuisi maupun menggunakan metode komputasi matematika, baik menggunakan metode sederhana maupun lanjut. Pada bahasan sub 
bab ini kita akan mempelajari beberapa karakteristik suatu portfolio yang meliputi nilai harapan keuntungan dan nilai resiko nya. Misalkan seorang investor memiliki sebuah portofolio yang terdiri dari $\mathrm{k}$ aset. Dinotasikan $p_{i j}$ adalah harga aset $j$ pada waktu $i$ dan didefinisikan return dari aset $j$ dalam satu periode waktu (harian, bulanan, tahunan, dsb) sebagai berikut

$$
r_{i j}=\frac{p_{i j}-p_{i-1 j}}{p_{i-1 j}}
$$

Selanjutnya data di atas dapat dituangkan dalam matriks $\mathbf{R}=\left(r_{i j}\right)$ dengan rata-rata $r$ bar dan variansi $\sum$. Diamati, vektor $\mathbf{r}=\left(r_{1}, \ldots \ldots, r_{k}\right)^{\mathrm{T}}$ menunjukkan rata-rata return masing-masing aset yang ada dalam portofolio. Variansi dan kovariansi dari masing-masing aset dinyatakan dengan matriks kovariansi $\Sigma$, yang elemenelemennya berisi variansi asset ke i $\left(\sigma_{\text {iii }}\right)$ dan kovariansi antara asset $\mathrm{i}$ dan asetj $\left(\sigma_{\mathrm{ij}}\right)$. Kovariansi digunakan untuk mengukur bagaimana dua peubah acak dalam hal ini return aset $i$ dan aset $j$ bergerak. Nilai kovariansi yang positif menunjukkan bahwa return kedua aset tersebut cenderung bergerak searah, sedangkan nilai kovariansi yang negative menunjukkan bahwa return kedua aset cenderung bergerak berlawanan arah. Nilai kovariansi yang kecil atau nol menunjukkan tidak ada hubungan antara kedua aset tersebut. Nilai kovariansi antara aset $i$ dan aset $j$ dapat ditulis sebagai berikut :

$$
\sigma_{i j}=\rho_{i j} \sigma_{i} \sigma_{j}
$$

dengan $\rho_{i j}$ adalah koefisien korelasi antara return aset $i$ dan return aset $j$.

\section{Expected Return dan Variansi Portofolio}

Tingkat keuntungan yang diharapkan (mean return) portofolio adalah harga harapan dari return portofolio $R_{p}$ yang merupakan adalah jumlahan tertimbang dari return masing-masing saham yaitu :

$$
R_{p}=w_{1} r_{1}+. .+w_{p} r_{p} .
$$

Sedangkan ekspektasi return portofolio adalah merupakan jumlahan tertimbang dari ekspektasi return masing-masing saham.

$$
\begin{aligned}
E\left(R_{p}\right) & =w_{1} E\left(r_{1}\right)+\ldots+w_{k} E\left(r_{k}\right) \\
& =w^{T} E(\tilde{r})
\end{aligned}
$$

Dimana $\quad \mathrm{W}=\left(w_{1}, \ldots, w p \quad\right)^{\mathrm{T}}$ menunjukkan bobot/komposisi aset-aset yang terbentuk dalam portofolio dan memenuhi jumlah sama dengan 1. Nilai ekspektasi return portofolio diestimasi dengan $w^{T} \boldsymbol{r}$. Dalam melakukan investasi dalam efek atau sekuritas, para investor dihadapkan pada unsur risiko dan ketidakpastian. Investor tidak mengetahui dengan pasti hasil yang akan dia dapatkan dari investasi yang dilakukannya. Yang bisa dia lakukan adalah memperkirakan berapa keuntungan yang diharapkan, dan seberapa jauh kemungkinan hasil yang sebenarnya nanti akan menyimpang dari hasil yang diharapkan atau seberapa besar resiko dari investasinya.

Selanjutnya akan dihitung rumus untuk risiko portfolio. Dalam lingkup teori portofolio, risiko dapat dinyatakan sebagai besarnya penyimpangan dari keuntungan portofolio. Resiko portofolio dihitung dari nilai volatilitas (risiko) suatu return portofolio yaitu variansi dari $R_{p}$ :

$$
\begin{aligned}
\operatorname{Var}\left(R_{p}\right) & =\operatorname{Var}\left(w^{\mathrm{T}} \mathbf{r}\right) \\
& =w^{\mathrm{T}} \operatorname{Var}(\mathbf{r}) w \\
& =w^{\mathrm{T}} \Sigma w
\end{aligned}
$$

Variansi suatu return portfolio dapat dirumuskan:

$$
\begin{aligned}
\sigma_{p}^{2} & =E\left(\overline{r_{p}}-E\left(\overline{r_{p}}\right)\right)^{2} \\
& =E\left(c_{1} r_{1}+\ldots+c_{n} r_{n}-E\left(c_{1} r_{1}+\ldots+c_{n} r_{n}\right)\right)^{2} \\
& =E\left(c_{1}\left(r_{1}-E\left(r_{1}\right)\right)+\ldots+c_{n}\left(r_{n}-E\left(r_{n}\right)\right)\right)^{2} \\
& =E\left(\begin{array}{l}
c_{1}^{2}\left(r_{1}-E\left(r_{1}\right)\right)^{2}+\ldots+c_{n}^{2}\left(r_{n}-E\left(r_{n}\right)\right)^{2} \\
+2 c_{1} c_{2}\left(r_{1}-E\left(r_{1}\right)\right)\left(r_{2}-E\left(r_{2}\right)\right) \\
+\ldots+2 c_{n-1} c_{n}\left(r_{n-1}-E\left(r_{n-1}\right)\right)\left(r_{n}-E\left(r_{n}\right)\right)
\end{array}\right) \\
& =\sum_{i=1}^{k} \sum_{j=1}^{k} c_{i} c_{j} \sigma_{i j}
\end{aligned}
$$$$
=c^{T} \Sigma c \text { Jadi, variansi (risiko) dari }
$$
portofolio yang terbentuk adalah $c^{\mathrm{T}} \Sigma c$. 
Dalam pembentukan portofolio efisien, asumsi perilaku investor yang wajar terjadi dalam keputusan investasi adalah investor yang cenderung menghindari risiko (risk averse). Investor yang risk averse adalah investor yang jika dihadapkan pada dua investasi dengan expected return yang sama dan risiko yang berbeda, maka ia akan memilih investasi dengan tingkat risiko yang lebih rendah. Jika seorang investor memiliki beberapa pilihan portofolio yang efisien, maka portofolio yang paling optimal-lah yang akan dipilihnya.

Pengertian portofolio optimal adalah portofolio yang dipilih seorang investor dari sekian banyak pilihan yang ada pada kumpulan portofolio yang efisien. Tentunya portofolio yang dipilih investor adalah portofolio yang sesuai dengan preferensi investor bersangkutan terhadap return maupun terhadap risiko yang bersedia ditanggungnya. $\mathrm{Di}$ sini diasumsikan preferensi investor terhadap risiko adalah risk averse (menghindari risiko), sehingga kita dapat mendefinisikan portofolio yang memiliki mean-variance efisien (mean-variance efficient portfolio) sebagai portofolio yang mempunyai variansi minimal dari rata-rata returnnya. Secara matematika hal tersebut sama dengan mengoptimalisasi bobot $\boldsymbol{w}=\left(w_{1}, \ldots, w_{p}\right)^{\mathrm{T}} \quad$ dengan meminimalkan variansi

$$
1 / 2 \mathbf{w}^{\mathrm{T}} \sum \mathbf{w}
$$

Pengambilan setengah dari kuantitas di atas hanyalah alasan teknis untuk memecahkan masalah optimisasi.

\section{Pembentukan Portofolio satu konstrain}

Rumus pembobotan portofolio optimal dapat diselesaikan dengan mendefinisikan variance efficient portfolio yakni portofolio yang membuat risiko (3.2) menjadi minimal dengan batasan jumlah dari bobot (weight) portofolio tersebut $\mathbf{w}^{\mathrm{T}} \mathbf{1}_{\mathrm{p}}=1$. Selanjutnya dapat dibentuk fungsi Lagrange $\mathrm{L}$, dan akan dicari $\boldsymbol{w}$ yang meminimalkan Fungsi Lagrange tersebut

$$
\mathrm{L}=1 / 2 \mathbf{w}^{\mathrm{T}} \Sigma \mathbf{w}-\lambda\left(\mathbf{w}^{\mathrm{T}} \mathbf{1}_{\mathrm{p}}-1\right)
$$

Fungsi Lagrange L diturunkan secara parsial terhadap $\boldsymbol{w}$ dan disama dengankan nol sebagai berikut :

$$
\begin{aligned}
\frac{\partial L}{\partial w^{T}} & =\frac{\partial}{\partial w^{T}}\left(\frac{1}{2} w^{T} \Sigma w-\lambda\left(w^{T} 1_{p}-1\right)\right) \\
& =\Sigma w-\lambda 1_{p}
\end{aligned}
$$

Turunan parsial $\mathrm{L}$ terhadap vector $\boldsymbol{w}=\left(w_{1}, \ldots, w_{p}\right)$ di atas, artinya adalah turunan parsial L terhadap masing-masing $w_{i}$, $i=1, \ldots$, p. Proses diferensiasi ini akan menghasilkan vector kolom berukuran $p$. Dengan menyamadengankan nol turunan di atas diperoleh hasil :

Sehingga diperoleh

$$
\boldsymbol{\Sigma} \boldsymbol{w}=\lambda \mathbf{1}_{\mathrm{p}}
$$

$$
\begin{aligned}
\boldsymbol{w}=\lambda \Sigma^{-1} \mathbf{1}_{\mathrm{p}} & =\frac{1}{2} \lambda^{2} 1_{p}{ }^{\mathrm{T}} \Sigma^{-1} 1_{p}-\lambda\left(\lambda 1_{p}{ }^{\mathrm{T}} \Sigma^{-1} 1_{p}-1\right) \\
& =\frac{1}{2} \lambda^{2} 1_{p}{ }^{\mathrm{T}} \Sigma^{-1} 1_{p}-\lambda^{2} 1_{p}{ }^{\mathrm{T}} \Sigma^{-1} 1_{p}+\lambda \\
& =\lambda-\frac{1}{2} \lambda^{2} 1_{p}{ }^{\mathrm{T}} \Sigma^{-1} 1_{p}
\end{aligned}
$$

Kuantitas tersebut merupakan fungsi dari $\lambda$. Jika $\mathrm{L}$ diturunkan terhadap $\lambda$ dan disama dengankan nol, maka diperoleh

$$
\lambda=\left(1_{p}^{T} \Sigma^{-1} 1_{p}\right)^{-1}
$$

Turunan kedua dari L terhadap $\boldsymbol{w}$,

$$
\frac{\partial^{2} L}{\partial w^{T} \partial w}=\Sigma>0
$$

Hal ini menunjukkan bahwa $\boldsymbol{w}$ yang diperoleh benar-benar akan meminimalkan nilai $\mathrm{L}$ di atas, dan $\mathbf{w}$ yang diperoleh akan memberikan risiko yang minimal dibandingkan dengan w yang lain. Dengan cara substitusi didapat solusi Fungsi Lagrange untuk mendapatkan nilai $\boldsymbol{w}$ yaitu :

$$
w=\frac{\Sigma^{-1} 1_{p}}{1_{p}{ }^{\mathrm{T}} \Sigma^{-1} 1_{p}}
$$

Berdasarkan pada hasil perhitungan matematis di atas, maka teorema dibawah ini yang sudah teruji kebenarannya melalui proses di atas. 


\section{Teorema}

Pembobotan pada mean-variance efficient portfolio dengan return $X \sim(\mu, \Sigma)$ adalah

$$
w_{o p t}=\frac{\Sigma^{-1} 1_{p}}{1_{p}^{\mathrm{T}} \Sigma^{-1} 1_{p}}
$$

Rumus di atas dapat digeneralisasi dalam pembobotan portofolio optimal kasus-kasus khusus ditinjau dari struktur variansi dan korelasi antar aset-asetnya.

\section{HASIL DAN PEMBAHASAN}

Penelitian ini menggunakan pendekatan kuantitatif dengan studi deskriptif dengan sumber https://hargapangan.id/tabelharga/pasar-modern/daerah. Banyak data dari 1 juni 2019 sampai 1 desember 2019. Tujuan penelitian ini adalah untuk mengukur dan menganalisis portofolio optimal investasi Komoditas Pangan di Kota Padang dengan menggunakan pendekatan mean variance. Hasil penelitian ini diharapkan dapat membantu Pedagang mengambil keputusan untuk menentukan, mengevaluasi, dan untuk memilih komposisi dan porsi/bobot investasi pada beberapa komoditas pangan.

Sebelum menentukan portofolio optimal dengan menggunakan metode mean variansi dilakukan langkah-langkah sebagai berikut:

\section{Menghitung return portofolio}

Data yang diolah adalah data return portofolio. Dinotasikan $p_{i j}$ adalah harga aset $j$ pada waktu $i$ dan didefinisikan return dari aset $j$ dalam satu periode waktu (harian, bulanan, tahunan, dsb) sebagai berikut:

$$
r_{i j}=\frac{p_{i j}-p_{i-1 j}}{p_{i-1 j}}
$$

Dari data return tersebut didapatlah ratarata dan variannya sebagai berikut:
Tabel 1. rata- rata dan varian

\begin{tabular}{|r|r|r|r|r|}
\hline Beras & $\begin{array}{l}\text { Telur } \\
\text { ayam }\end{array}$ & $\begin{array}{l}\text { Minyak } \\
\text { goreng }\end{array}$ & $\begin{array}{l}\text { Gula } \\
\text { pasir }\end{array}$ & $\begin{array}{l}\text { Cabe } \\
\text { merah }\end{array}$ \\
\hline $0.29 \%$ & $-0.01 \%$ & $0.03 \%$ & $0.01 \%$ & $0.42 \%$ \\
\hline $0.22 \%$ & $0.00 \%$ & $0.00 \%$ & $0.01 \%$ & $0.23 \%$ \\
\hline
\end{tabular}

Berdasarkan data historis, secara rata-rata individual return yang terbesar berasal dari Cabe merah $(0,42 \%)$, disusul oleh beras $(0,29 \%)$, minyak goreng $(0,03 \%)$, gula pasir $(0,01 \%)$, terakhir telur ayam $(-0,01)$. Berdasarkan hasil pengamatan nilai return aktual terlihat bahwa nilai return yang dihasilkan mengandung ketidakpastian. Nilai return dari setiap saham berbedaberbeda dan tidak selalu bernilai positif.

\section{Menghitung covariansi portofolio}

Covariance merupakan ukuran dari seberapa banyak dua set data yang berbeda-beda. Covariance menentukan sejauh mana dua variabel yang berkaitan atau bagaimana mereka bervariasi bersama. Covariance merupakan rata-rata dari hasil dari penyimpangan dari titik data masing-masing mean. Variansi dan kovariansi dari masing-masing aset dinyatakan dengan matriks kovariansi $\Sigma$, yang elemen-elemennya berisi variansi asset ke i $\left(\sigma_{\mathrm{ii}}\right)$ dan kovariansi antara asset i dan asetj $\left(\sigma_{\mathrm{ij}}\right)$. Dari data tersebut didapatlah kovariansi dari masing-masingnya adalah sebagai berikut:

Tabel 2. Nilai Kovariansi

\begin{tabular}{|l|r|}
\hline cov(beras-telur ayam) & $-2.5 \mathrm{E}-05$ \\
\hline cov(beras-minyak goreng) & $1.14 \mathrm{E}-06$ \\
\hline cov(beras-gula pasir) & $-3.2 \mathrm{E}-05$ \\
\hline cov(beras-cabe merah) & 0.002091 \\
\hline cov(telur ayam-minyak goreng) & $9.73 \mathrm{E}-08$ \\
\hline cov(telur ayam-gula pasir) & $3.15 \mathrm{E}-05$ \\
\hline cov(telur ayam-cabe merah) & $-4.1 \mathrm{E}-05$ \\
\hline cov(minyak goreng-gula pasir) & $2.12 \mathrm{E}-08$ \\
\hline cov(minyak goreng-cabe merah) & $1.37 \mathrm{E}-06$ \\
\hline cov(gula pasir-cabe merah) & $-6.9 \mathrm{E}-05$ \\
\hline cov(beras-beras) & 0.004511 \\
\hline cov(telur ayam-telur ayam) & $1.6 \mathrm{E}-05$ \\
\hline $\begin{array}{l}\text { Cov(minyak goreng-minyak } \\
\text { goreng) }\end{array}$ & $7.51 \mathrm{E}-07$ \\
\hline cov(gula pasir-gula pasir) & 0.000348 \\
\hline cov(cabe merah-cabe merah) & 0.003511 \\
\hline
\end{tabular}




\section{Menyusun covariansi portofolio menjadi matriks persegi variansi kovariansi}

Tabel 3. Matrik persegi variansi kovariansi

\begin{tabular}{|c|c|c|c|c|c|}
\hline & indf & bbni & bisi & bdmn & pnbn \\
\hline indf & $\begin{array}{c}0.00451 \\
1\end{array}$ & $-2.5 \mathrm{E}-05$ & $\begin{array}{c}1.14 \mathrm{E} \\
-06\end{array}$ & $-3.2 \mathrm{E}-05$ & 0.00209 \\
1
\end{tabular}

\section{Menghitung invers dari marikts persegi variansi kovariansi}

Tabel 4. Invers matrik variansi kovariansi \begin{tabular}{|l|l|l|l|l|l|}
\hline 306.2028 & -1.38824 & -131.791 & 0.028022 & -182.293 \\
\hline
\end{tabular} \begin{tabular}{|lll|l|l|l|l|l|}
\hline-1.38824 & -95.7747 & -18.6846 & 525.9419 & 10.04206 \\
\hline
\end{tabular} \begin{tabular}{|l|l|l|l|l|l|}
-131.791 & -18.6846 & 1332726 & -79.2522 & -443.556 \\
\hline
\end{tabular} \begin{tabular}{lllllll|}
\hline 0.028022 & 525.9419 & -79.2522 & -4.29369 & 6.114914 \\
\hline
\end{tabular} -182.293 10.04206-443.556 6.114914 393.7795

\section{Menghitung bobot}

$$
w_{o p t}=\frac{\Sigma^{-1} 1_{p}}{1_{p}{ }^{\mathrm{T}} \Sigma^{-1} 1_{p}}
$$

Berdasarkan rumus tersebut, untuk menghitung bobot hal pertama yang dilakukan adalah menghitung pembilang dengan cara mengalikan antara invers kovariansi dengan matriks indentitas yang bersesuaian sehingga didapat matrisk baris sebagai berikut:

Tabel 5. Matrik baris

\begin{tabular}{|l|l|l|l|l|}
\hline-9.24166 & 420.1364 & 1332053 & 448.5389 & -215.912 \\
\hline
\end{tabular}

Kemudian menghitung penyebutnya dengan cara mengalikan antara transpos matriks identitas, invers kovariansi dan matriks identitas yang bersesuaian sehingga didapat hasilnya skalar yaitu sebesar 1332696. Setelah itu dihitunglah bobotnya masing-masing dengan cara membagi (Perkalian antara invers kovariansi dan matriks indentitas yang bersesuaian/ Perkalian antara transpos matriks identitas, invers kovariansi dan matriks identitas yang bersesuaian)

Tabel 6. Bobot masing-masing

\begin{tabular}{|l|l|l|l|l|}
\hline Beras & Telur & $\begin{array}{l}\text { Minyak } \\
\text { goreng }\end{array}$ & $\begin{array}{l}\text { Gula } \\
\text { pasir }\end{array}$ & $\begin{array}{l}\text { Cabe } \\
\text { merah }\end{array}$ \\
\hline $0.00 \%$ & $0.03 \%$ & $99.95 \%$ & $0.04 \%$ & $-0.02 \%$ \\
\hline
\end{tabular}

Komposisi instrumen W1, W2, W3, W4 dan W5 di atas merupakan komposisi portofolio yang memiliki risiko paling rendah dari seluruh peluang diversifikasi yang ada. Komposisi portofolio tersebut di atas akan menghasilkan risiko atau standar deviasi sebesar 0,0000008 dan expected return sebesar -0,0000224. Dari kelima instrumen yang tersedia, terlihat bahwa porsi minyak goreng $(99,95 \%)$, telur $(0,03 \%)$, gula pasir $(0,04 \%)$, dan cabe merah bernilai negatif $(-0,02 \%)$ berarti terdapat short sale dalam pembobotan Mean Varians. Short sale merupakan penjualan komoditas yang tidak dimiliki oleh investor tetapi dipinjam terlebih dahulu dari pedagang lain. Ide Short sale adalah menjual sekarang dengan harga mahal, embeli nanti dengan harga murah. Sementara untuk beras disini bobotnya bernilai $0.00 \%$ yang artinya beras tidak disarankan untuk investasi pangan, karena kalau kita lihat dari data historisnya beras tidak mengalami fluktuasi sedikitpun, artinya harga beras konstan. Kemudian dari kombinasi bobot komoditas tersebut bisa kita perkirakan keuntungan harapan senilai $-0,0024 \%$. Nilai negatif berarti mengalami kerugian sebesar 0,0024\%. Dan resiko sebesar 0,0001\%. Walaupun disini keuntungan harapannya bernilai negatif tetapi inilah portofolio opetimal yang dibentuk dengan menggunakan metode mean variance.

\section{SIMPULAN}

Portofolio merupakan kombinasi atau gabungan atau sekumpulan aset baik berupa aset real atau assets finansial yang dimiliki oleh investor. Pada penelitian ini digunakan metode Mean Varians Estimation Portofolio untuk menghitung bobot dari portofolio. Data yang digunakan dalam penelitian ini adalah data harga pangan 
yang diambil dari 5 bahan pangan yaitu beras, telur, minyak goreng, gula pasir dan cabe merah. Dari pengolahan data didapat bahwa porsi minyak goreng $(99,95 \%)$, telur $(0,03 \%)$, gula pasir $(0,04 \%)$, cabe merah bernilai negatif $(-0,02 \%)$, dan beras $(0.00 \%)$. Minyak goreng mendapatkan bobot yang terbesar. Hal ini dikarenakan fluktuasi yang ada pada data historis, dalam data tersebut harga tertinggi minyak goreng per $\mathrm{kg}$ adalah Rp. 16.600,00 dan harga terendahnya adalah Rp. 15.900,00. Sedangkan untuk beras bobotnya bernilai $0,00 \%$, hal ini dikarenakan harga beras konstan pada harga Rp. 15.950,00.

\section{SARAN}

Karena berbagai keterbatasan, penulis menyadari penelitian dan tulisan ini masih banyak kekurangannya. Banyak hal yang belum tercakup dalam penelitan ini. Perlu dikaji lebih lanjut untuk pengembangan metode lain dengan memiliki return portofolio tinggi dan resiko portofolio yang rendah dengan memilih aset-aset terbaik untuk pembentukan portofolio yang lebih optimal.

\section{DAFTAR PUSTAKA}

[1] Anton, H. (2000). Dasar-dasar Aljabar Linear Elementer. Jakarta: Erlangga.

[2] https://hargapangan.id/tabel-harga/ pasar-modern/daerah

[3] Jogianto. (2003). Teori Portofolio dan Analisis Investasi Edisi ke-tiga. Yogyakarta: BPFE.

[4] Rizki, Setyo Wira., Bujang Rusli, dan Evy Sulistianingsih. (2018). Analisis Portofolio Optimal Pada Index Saham LQ 45 dengan Multi-Index Models. Journal Buletin Ilmiah Mat. Stat. dan Terapannya (Bimaster) Volume 07, No. 2 (2018), hal 135 - 140 .

[5] Suharsono, Sri Dewi. (2015). Perbandingan Metode Mean Variance Efficient Portofolio (MVEP) dan Model
Indeks Tunggal Pada Saham Jakarta Islamic Index (JII). Yogyakarta: UIN Sunan Kalijaga. 